\title{
Prevalence of Vaginitis among Women Attending Antenatal Care Centre of Wudil General Hospital, Kano State Nigeria
}

\author{
${ }^{1}$ Aliyu, A. S., ${ }^{2}$ Abdulmalik, I., ${ }^{2}$ Shamsiyya, M. S., ${ }^{1}$ Lambu, Z. N. ${ }^{3}$ Sabo, A. and ${ }^{1}$ Haruna, \\ H. B. \\ ${ }^{1}$ Department of Microbiology, Kano University of Science and Technology, Wudil \\ ${ }^{2}$ Medical Education Unit, College of Medicine, Kaduna State University \\ ${ }^{3}$ Department of Biological Science, Kano University of Science and Technology, Wudil \\ Corresponding Author Email: aliyujanzaki@gmail.com
}

\begin{abstract}
Vaginitis is usually caused by a change in the normal balance of vaginal microbes, an infection or reduced oestrogen levels after menopause leading to variety of infections by bacteria, fungi and viruses. The study aimed to determine the prevalence of vaginitis and its associated risk factors among women attending antenatal care center of Wudil general hospital, Kano Nigeria. A total of 352 High Vaginal Swab and serum samples were collected from women attending antenatal care centre of Wudil general hospital. The samples were processed and screened for the presence of Candida albicans, Trichomonas vaginalis and Treponema pallidum through culture and microscopy and serum venereal disease research laboratory (VDRL) test. The risk factors were assessed using a designed questionnaire and analysed using Multivariate logistic modelling. The prevalence of $C$. albicans, $T$. vaginalis and Treponema pallidum were found to be $32.38 \%, 18.46 \%$, and $4.83 \%$, respectively $(p \leq 0.05)$. The result showed that the risk factors that are significantly associated with the prevalence of vaginitis were active sex age $(26-30)$ years, educational status and number of participants husband's wives. The study identifies that $C$. albicans is the major cause of vaginitis, and is insignificantly associated with active sex age educational status and number of participants husband's wives.

Keywords: Candida albicans, Trichomonas vaginalis, Treponema pallidum, Pregnant Women
\end{abstract}

INTRODUCTION

Vaginitis is a common medical problem in women that is associated with substantial discomfort and frequent medical visits, roughly 5 to 10 million hospital visits per year are attributed to vaginitis (Novakowska et al., 2004). Moreover, the availability of over-thecounter medications for fungal vaginitis has increased the likelihood that women will come to medical attention with partially or inadequately treated infections (Adetunde et al., 2011).

The vaginal ecosystem undergoes major compositional changes throughout a woman's life. From childhood until puberty, the limited presence of esterogen implies a low bacterial content in the vagina, which occurs during reproductive years (Mohanty et al., 2007). On the other hand, during menopause, as estrogen levels drop, not only the epithelial fragility of vaginal mucosa is affected, due to the decrease of thickness of the different cellular layers, it also becomes susceptible to infectious diseases (Deorukhkar and Saini, 2013). Therefore the vagina loses much of its self-cleaning ability

UMYU Journal of Microbiology Research and natural defenses hence the privilege of vaginitis.

Vaginitis may be due to infectious agents including bacteria such Treponema pallidum; protozoans like Trichomonas vaginitis and fungi such as Candida albicans (Abdulsadah et al. 2014). Accurate diagnosis of the etiological agent and determination of the susceptibility pattern of the agent to certain antibiotic pose a significant effect while dealing with antimicrobial drugs resistance (Dharma et al., 2013).

Candida albicans, Treponema pallidum and Trichomonas vaginalis are the most common cause of vaginitis causing vaginal discharge, vaginal and vulval pruritis, dysuria and dyspareunia (Bradshaw et al., 2012). Candida yeast is the most common cause of opportunistic mycoses worldwide (Ahmad et al., 2016).

Culture is considered as the "gold standard" in diagnosing Candida vaginitis. It can also be diagnosed by microscopic detection of yeast cells on a vaginal smear along with the presence of a white, mucous-like vaginal discharge on physical examination. 


\section{UJMR, Volume 6 Number 1, June, 2021, pp 18 - $23 \quad$ ISSN: 2616 - 0668}

Saline or $10 \% \mathrm{KOH}$ wet mount may show yeast cells and pseudohyphae (Bradshaw et al., 2012). Candida culture is usually done on Sabouraud's dextrose agar and Gram stain of the colony shows gram positive yeast cells. Germ tube test can be used for differentiation of Candida albicans species from nonalbicans species. Candida spp. can also be identified serologically, using specific antisera. DNA probes are also available for Candida spp detection (Dariane et al., 2012).

Trichomonas vaginitis is more often difficult to diagnose because of its heterogeneous presentation. Vaginal $\mathrm{pH}$ is often more than 4.5. Many cases give a positive amine $(\mathrm{KOH})$ test ("whiff" test). T. vaginalis was traditionally diagnosed via a wet mount, in which polymorphonuclear response and a "corkscrew" motility can be observed (Alli et al., 2011). The most common method of diagnosis is by culture. Despite the low cost, culture of trichomonas is not routinely practised in many laboratories. Culture requires Diamond's medium. The In Pouch TV culture system is now found to be a good alternative to traditional culture techniques. Other methods like rapid antigen testing and transcription-mediated amplification are not in widespread use (Kissinger and Adamski, 2013). The presence of $T$. vaginalis can also be diagnosed by direct fluorescent antibody test, enzyme immune assay and PCR.

Treponema pallidum is most commonly spread bacteria through sexual activity. It may also be transmitted from mother to baby during pregnancy or at birth, resulting in congenital syphilis (Akinbiyi et al., 2008). Diagnosis is usually made by using blood tests; the bacteria can also be detected using dark field microscopy.

While interventions aiming at promoting safer sex, such as condom use, and vaginitis etiological diagnosis and treatment, in high risk populations are widely accepted and advocated for (Abdulsadah et al., 2014). It's also possible that sexual practices influence $C$. albicans infection, as well as other reproductive tract infections (Gill et al., 2011; Ballini et al., 2012). While the requirements for $T$. vaginalis to develop itself in the genital tract vary from those for $C$. albicans and $T$. pallidum, the coexistence of these two or three microorganisms in the genital tract has been discovered in several women (Levi et al., 2011; Lopez-Monteon et al., 2013). There has been no record of this incident in the general hospital in Wudil, as far as we know.
As a result, the aim of this analysis was to evaluate the etiological agent of vaginitis, the rate of incidence, and potential risk factors among Wudil general hospital's female patients.

\section{MATERIAL AND METHODS}

Ethical clearance for the study was obtained from Kano state ministry of health. High Vaginal Swab and serum samples were aseptically collected through the assistance of the medical personnel from 352 randomly selected women attending antenatal care centre of Wudil general hospital, Kano.

The samples were aseptically collected using sterile cotton swab stick and venipuncture and labelled appropriately. Patient's information regarding their ages, pregnancy age, educational level and number of participants' husband's wives were documented using questionnaire. Samples collected were immediately transported to the laboratory unit of Wudil general hospital for immediate analysis (Gill et al., 2011; López-Monteon et al., 2013).

Identification of Trichomonas vaginalis

The presence of Trichomonas vaginalis in the sample was detected using wet mount preparations according to the methods described by Akinbo et al. (2017). A small portion of the swab was suspended in one drop of $0.85 \%$ physiological saline on a slide and covered with a cover slip. The wet mount preparation was then examined for the characteristic morphology and darting motility under X10and X40 objectives.

Isolation and Identification of Candida albicans

The swab samples were inoculated each on the surface of previously dried Sabouraud dextrose agar plate as described by Uzoh et al. (2016). The plates were incubated at room temperature for 48 hours and were examined for white cream colonies characteristic of Candida spp. Small inoculum of suspected Candida cultures was inoculated into $0.5 \mathrm{ml}$ of human serum in a test tube and was incubated at $37^{\circ} \mathrm{C}$ for 3hours. After incubation, a loopfull of culture was placed on a glass slide, overlaid with a cover-slip and was then examined microscopically for the presence or absence of germ-tubes. Formation of germ tubes was seen as long tube like projections extending from the yeast cells with no constriction or septa at the point of attachment to the yeast cells. This is a confirmatory test for the identification of Candida albicans (Saha et al., 2018). 
Venereal Diseases Research Laboratory Test for Antibodies/Antigens of Treponema pallidum

The VDRL test was carried out to detect antibodies/antigens of Treponema pallidum according to the methods described by Rapikit Neclife, (2019). The blood sample was centrifuge to obtain the serum. Two drops of serum was placed into the sample window using provided disposable dropper. Appearance of two colour line in both control and test region indicated a positive results.

\section{RESULTS}

The result of the study revealed that out of the 352 studied samples, $114 \quad(32.38 \%)$ were identified as C. albicans, $65(18.46 \%)$ as $T$. vaginalis and $17(04.83 \%)$ were Treponema pallidum positive (VDRL+) (Table 1).

TABLE 1: Prevalence of $C$. albicans, $T$. vaginalis and $T$. pallidumamong Women Attending Antenatal Care Centre of Wudil General Hospital

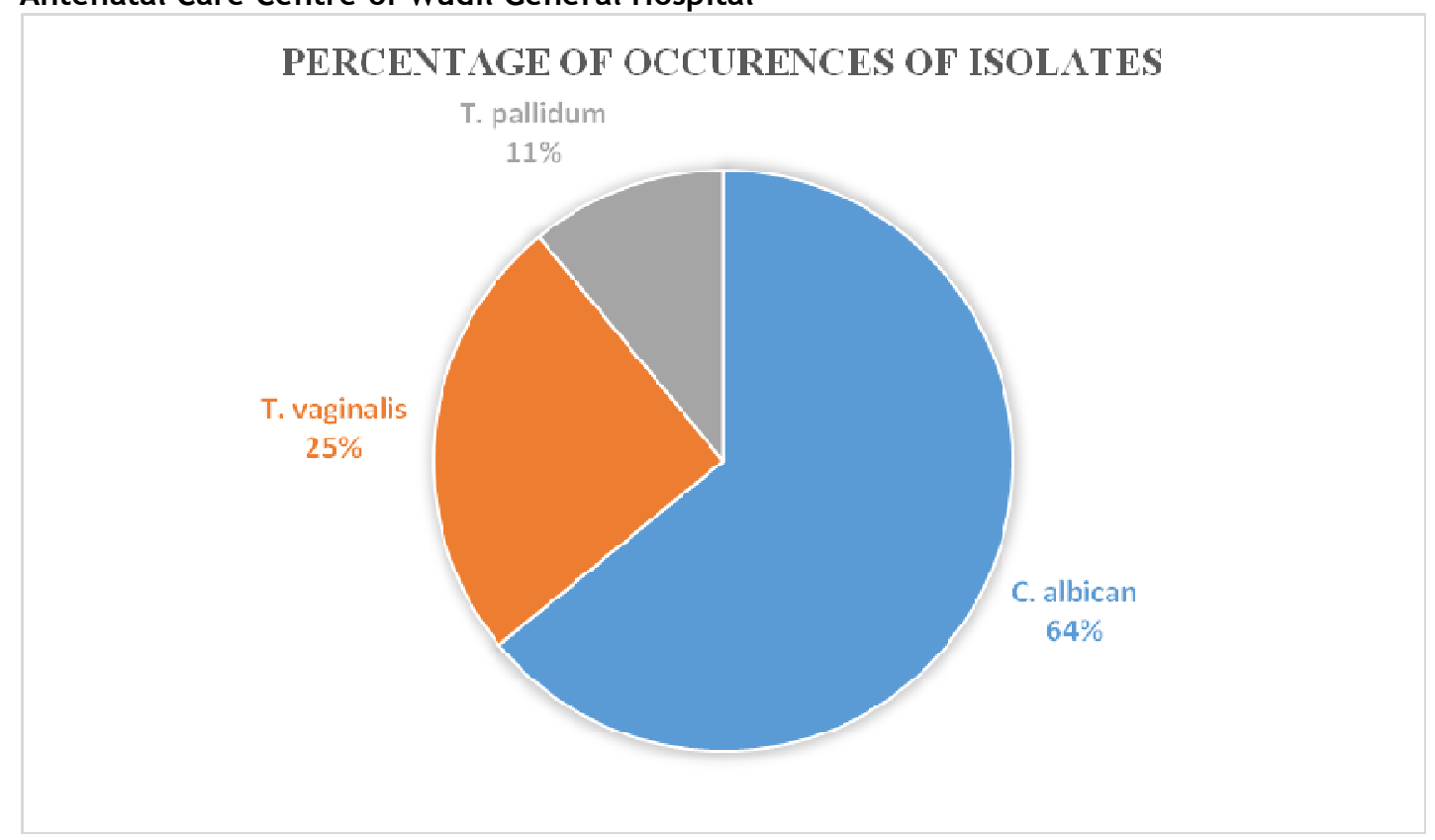

Findings also shows that age range $26-30$ had the highest prevalence rate of $71(20.17 \%)$ of which 41 (11.6\%) were identified as C. albicans, $23(6.53)$ as $T$. vaginalis and $7(1.99 \%)$ T. pallidum while least positive prevalence $18(5.11 \%)$ was at age range of $31-35$ with $6(1.70 \%)$ for C. albicans, 7 (1.99\%) T. vaginalis and 5 (1.42\%) T. pallidum (Table 2 )

TABLE 2: Prevalence $C$. albicans, $T$. vaginalis and $T$. pallidum in Relation to Age

\begin{tabular}{cccccc}
\hline $\begin{array}{l}\text { Age group } \\
\text { (years) }\end{array}$ & No. sampled & $\begin{array}{c}\text { No. Positive } \\
(\%)\end{array}$ & $\begin{array}{c}\text { C. albicans } \\
(\%)\end{array}$ & $\begin{array}{c}\text { T. vaginalis } \\
\text { (\%) }\end{array}$ & T. pallidum (\%) \\
\hline $16-20$ & 81 & $29(8.23)$ & $21(5.97)$ & $8(2.27)$ & $0(0)$ \\
$21-25$ & 93 & $44(12.5)$ & $28(7.95)$ & $13(3.69)$ & $3(0.85)$ \\
$26-30$ & 103 & $71(20.17)$ & $41(11.65)$ & $23(6.53)$ & $7(1.99)$ \\
$31-35$ & 43 & $18(5.11)$ & $6(1.70)$ & $7(1.99)$ & $5(1.42)$ \\
$>35$ & 32 & $34(9.66)$ & $18(5.11)$ & $14(3.98)$ & $2(0.57)$ \\
Total & 352 & $\mathbf{1 9 6 ( 5 5 . 6 8 )}$ & $\mathbf{1 1 4 ( 3 2 . 3 8 )}$ & $\mathbf{6 5 ( 1 8 . 4 6 )}$ & $\mathbf{1 7}(4.83)$ \\
\hline
\end{tabular}

Moreover, highest positive prevalence of 83 $(23.58 \%)$ was among women with none number of co-wives, 54 (15.35\%) were identified as $C$. albicans, $23(6.33 \%)$ as $T$. vaginalis and 6 (1.70\%) T. pallidum whereas category women with three co-wives revealed the least positive prevalence of $10(2.84 \%), 6(1.70 \%)$ were identified as $C$. albicans and $4(1.14 \%)$ as $T$. vaginalis (Table 3 ). 
UJMR, Volume 6 Number 1, June, 2021, pp 18 - $23 \quad$ ISSN: 2616 - 0668

TABLE 3: Prevalence of C.albicans, T.vaginalis and T. Pallidum in Relation to Number of Cowives

\begin{tabular}{cccccc}
\hline No. of Co-Wives & $\begin{array}{c}\text { No. sampled } \\
(\%)\end{array}$ & No. Positive (\%) & $\begin{array}{c}\text { C. albicans } \\
(\%)\end{array}$ & T. vaginalis (\%) & $\begin{array}{c}\text { T. pallidum } \\
(\%)\end{array}$ \\
\hline None & $147(41.76)$ & $83(23.58)$ & $54(15.35)$ & $23(6.53)$ & $6(1.70)$ \\
One & $128(36.36)$ & $71(20.17)$ & $35(9.94)$ & $27(7.67)$ & $9(2.56)$ \\
Two & $59(16.76)$ & $32(9.09)$ & $19(5.39)$ & $11(3.12)$ & $2(0.57)$ \\
Three & $18(5.11)$ & $10(2.84)$ & $6(1.70)$ & $4(1.14)$ & $0(0)$ \\
Total & $352(100)$ & $196(55.68 \%)$ & $114(32.38)$ & $65(18.46)$ & $17(4.83)$ \\
\hline
\end{tabular}

Furthermore, highest positive prevalence of 84 (23.85\%) was found among women with secondary education, $47(13.35 \%)$ were identified as C. albicans, $26(7.38 \%)$ as $T$. vaginalis and $11(3.12 \%)$ as $T$. pallidum. While women with Islamiyya education has the least positive prevalence of $20(5.69 \%), 11(3.13 \%)$ and 9 (2.56\%) (Table 4).

Findings also shows the co-prevalence of 53 $(15.06 \%)$ for C. albicans and T. vaginalis, 23 $(6.53 \%)$ for C. albicans and T. pallidum, 16 (4.55\%) for $T$. vaginalis and $T$. pallidum (Table $5)$.

TABLE 4: Prevalence of vaginitis in Relation to Educational Status of the Participants

\begin{tabular}{cccccc} 
Status & No. sampled (\%) & No. Positive (\%) & C. albicans (\%) & T. vaginalis (\%) & T. pallidum(\%) \\
\hline Islamiyya & $37(10.51)$ & $20(5.69 \%)$ & $11(3.13)$ & $9(2.56)$ & $0(0)$ \\
Primary & $118(33.52)$ & $61(17.32 \%)$ & $41(11.64)$ & $18(5.11)$ & $2(0.57)$ \\
Secondary & $151(42.90)$ & $84(23.85 \%)$ & $47(13.35)$ & $26(7.38)$ & $11(3.12)$ \\
Tertiary & $46(13.07)$ & $31(8.81 \%)$ & $15(4.26)$ & $12(3.41)$ & $4(1.14)$ \\
Total & $352(100)$ & $196(55.68 \%)$ & $114(32.38)$ & $65(18.46)$ & $17(4.83)$ \\
\hline
\end{tabular}

TABLE 5: Co infection OF C. albicans, $T$. vaginalis and $T$. pallidum among the Participants. Agents Co-infection(\%)

$\begin{array}{lc}\text { C. albicans } & 53(15.06) \\ \text { T. vaginalis } & \\ \text { C. albicans } & 23(6.53) \\ \text { T. pallidum } & \\ \text { T. vaginalis } & 16(4.55) \\ \text { T. pallidum } & \\ \text { C. albicans } & 0(0) \\ \text { T. vaginalis } & \\ \text { T. pallidum } & \end{array}$

DISCUSSION

Result of this study revealed a significant difference between the prevalence of $C$. albicans compared to $T$. vaginalis and $T$. Pallidum at $(P \leq .05)$ base on the frequency of occurrence. This is line with the study of Alo et al., (2012) in Abakaliki and Aniebue et al. (2018) in Enugu with $(43.00 \%)$ and $(49.53 \%)$ all in Nigeria, this is attributed to the nature of tight under wares use in the vaginal area leading to formation of moisture in combination with organic releases that favour the growth and multiplication of $C$. albicans in the area. Less prevalence of $T$. pallidum among the participants was in agreement with the finding of Bakare et al., (2002) in Ibadan, Dada et al., (1998) in Lagos, Aboyeji and Nwabuisi, (2003) and that of Taiwo et al., (2006) all in Nigeria who's reported a prevalence range of $0.125 \%$ to $4.1 \%$.

The higher percentage prevalence of all the three agent of vaginitis found within the age range of 26 - 30 years agree with the finding of Garba et al. (2014) in Nigeria who reported vaginitis to be most prevalent among 26-30 age group $(35.8 \%)$ and least in $>40$ years age group (10.5\%). This prevalence might be attributed to most active reproductive age group and high sexual 
Throughout this period, the ovary produces excessive amount of estrogen, which favours the growth of microbes by maintaining the acidic $\mathrm{pH}$ in the vagina and enhancing the yeast adherence to vaginal epithelial cells (Adetunde et al. 2011). This also explains why there is lower prevalence at age 45years and above.

The higher prevalence of $C$. albicans among tho se without a partner could be due to their lifest yle rather than cross infection, as one would $\mathrm{pr}$ edict given the higher prevalence of $T$. vaginali $s$ and $T$. pallidum among those with one partne r.

Correspondingly, women with secondary educational level had the highest vaginitis prevalence of $23.85 \%$ which differs from Ibrahim et al. (2014), who recorded the highest prevalence of $54 \%$ in those with primary education in Maiduguri, Nigeria. The low economic status, lack of education, lack of a female consultant at the health service center, hesitance to approach medical service, and sociocultural structure might be the cause of higher prevalence of vaginitis among less educated women while life style is the major cause of higher prevalence in educated women. Correlation of $C$. albicans and $T$. vaginalis coinfection shows a prevalence of co-infection of $53(15.06 \%)$. This high rate of co-infection

\section{REFRENCES}

Abdulsadah, A. R., Russu, W. and Kadhim, H. S. (2014). Prospective study of Trichomonas vaginalis infection. Sch. J. App. Med Sci. 2(1): 455-460.

Aboyeji, A. P. and Nwabuisi, C., J. (2003). Prevalence of sexually transmitted diseases among pregnant women in Ilorin, Nigeria. Journal of Obstet Gynaecol. 2(3): 637-9.

Adetunde, L. A., Glover, R. K. L. and Awo, 0. (2011). The Investigation of Candida albicans infections among teenagers (between the ages of 13-19) reporting at the Tamale Teaching Hospital (TTH) with vaginal discharge problems. International Journal of Research in Environmental Science and Technology4: 47-51.

Ahmad, M. M., Yahaya, G., Shu'aibu, I., Abdullahi, I. (2016). Urinary tract infections among female patients attending Birnin Kudu General Hospital, Jigawa, Nigeria. Dutse Journal of Pure and Applied Sciences2(1): 166-170.

Akinbiyi, A. A., Watson, R. and Feyi-Waboso, P. (2008). Prevalence of Candida albicans and bacterial vaginosis in asymptomatic pregnant women in South Yorkshire, recorded in this work is lower than that observed by Alo et al., (2012) and (2016) who recorded a high prevalence co-infection rate of $(43.00 \%)$ and $(32.14 \%)$ in Abakaliki and Ebonyi respectively. Also correlation of $C$. albicans and Syphilis co-infection shows a prevalence of coinfection of $23(6.06 \%)$

\section{CONCLUSION}

C. albicans was the major etiological agent of vaginitis isolated in this study followed by $T$. vaginalis and to a lesser effect T. pallidum. Coinfections of $C$. albicans with $T$. Vaginalis were high compared to other possible co-infection and no case of co-infection with both the three agents recorded. Since high prevalence were noticed within the age $(26-30)$ when one is very sexually active, which concurs with the utmost of one's reproductive life, there is need for a quick and rapid cognizance campaign for infection prevention and control as this will lead to barrenness, fatal wastage and even divorce if left untreated. The low economic status, lack of hygiene education, lack of a female consultant at the health service center, hesitance to approach medical service, and sociocultural structure were the predisposing factors for vaginitis in the study area.

United Kingdom. Archives of Gynecology and Obstetrics27(8): 463464.

Akinbo, F. O., Mokobia, C. N. and Ande, A. B. (2017). Prevalence of trichomoniasis among pregnant women in Benin City. Sahel Med J 20: 67-71.

Alli, J., Okonko, I., Odu, N., Kolade, A. and Nwanze, J. (2011). Detection and prevalence of Candida isolates among patients in Ibadan, Nigeria. Journal of Microbiology and Biotechnology Research1(3): 176-184.

Alo, M. N., Anyim, C., Onyebuchi, A. K., Okonkwo, E. C. (2012). Prevalence of asymptomatic Co-Infection of Candidiasis and Vaginal Trichomoniasis among Pregnant Women in Abakaliki, South-Eastern Nigeria.Journal of Natural Sciences Research2: 87-91.

Aniebue, U. U., Nwankwo, T. O. and Nwafor, M. I. (2018). Vulvovaginal candidiasis in reproductive age women in Enugu Nigeria, clinical versus laboratoryassisted diagnosis. Niger J Clin 21(10): 17-22.

Anuradha, M.C. Joanna, K. and Praveena, M. (2015). Prevalence of Trichomonas vaginalis Infection in Women of 
Reproductive Age Group. Int. J. Microbiol. Sci 4(12): 42-49.

Bakare, R. A., Oni, A. A., Umar, U. S., Adewole, I. F., Shokunbi, W. A., and Fayemiwo, S. A. (2002). Pattern of sexually transmitted diseases among commercial sex workers (CSWs) in Ibadan, Nigeria. Afr J Med Med Sci 3(1): 243-7.

Ballini, A., Cantore, S., Fatone, L., Montenegro, V., De Vito, D., Pettini, F., (2012). Transmission of nonviral sexually transmitted infections and oral sex. J Sex Med. 9(2):372-84.

Bradshaw, C. S. Pirotta, M., De Guingand, D., Hocking, J. S., Morton, A. N., Garland, S. M., Fehler, G., Morrow, A. and Walker, S. (2012). "Efficacy of oral metronidazole with vaginal clindamycin or vaginal probiotic for bacterial vaginosis: randomised placebo-controlled doubleblind trial". PLOS ONE. 7(4): e34540.

Dada, A. J., Ajayi, A. O., Diamondstone, L., Quinn, T. C., Blattner, W. A. and Biggar, R. J. (1998). A serosurvey of Haemophilus ducreyi, syphilis, and herpes simplex virus type 2 and their association with human immunodeficiency virus among female sex workers in Lagos, Nigeria. Sex Transm Dis. 25: 237 - 42.

Dariane, C. P., Luana, T. H. B., Luciane, N. C. and Alexandre, M. F. (2012). A six year epidemiological survey of Vulvovaginal Candidiasis in cytopathology reports in the state of Rio grandedosul, Brazil.Abr.41(2): 163-168.

Deorukhkar S., C. and Saini S. (2013). Vulvovaginal Candidiasis due to non albicans Candida: its species distribution and antifungal susceptibility profile. Int. J. Curr. Microbiol. App. Sci, 2(12): 323328.

Dharma, M. N. Vijaya, K. M., Umashankar, S., Abed Gulab, N., Kavitha, G. (2013). Prevalence of the Trichomonas Vaginalis in a Tertiary Care Hospital in Rural Bangalire, Southern India. Journal of Clinical and Diagnostic Research. 7(7): 1401-1403.

Garba, D. J., Zabaze, S., Vem, S., Tabitha, G., James, G. and Makshwar, K. (2014). "Microbiological Diagnosis of Bacterial Vaginosis in Pregnant Women in a Resource Limited Setting in North Central Nigeria," American Journal of Life Sciences 2(6): 356.

Gill, A. R., Ravanfar, P., Mendoza, N., Tyring, S. K. (2011). Sexual Behavior and Psychological Aspects Associated with Sexually Transmitted Infections. Sexually Transmitted Infections and Sexually
Transmitted Diseases. Berlin, Heidelberg: Springer Berlin Heidelberg. Pp. 35-42.

Ibrahim, S. M., Bukar, M., Galadima, G. B., Audu, B. M. and Ibrahim, H. A. (2014). "Prevalence of bacterial vaginosis in pregnant women in Maiduguri, NorthEastern Nigeria," Nigerian Journal of Clinical Practice 17(2): 154-158.

Ikeme, A. C. and Okeke, T. C. (2006). The relevance of VDRL as routine test in pregnant women: a critcal study. Niger $J$ Clin Pract. 9:65-7.

Kissinger, P. and Adamski, A. (2013). "Trichomoniasis and HIV interactions: a review". Sexually Transmitted Infections. 89 (6): 426-33.

Levi, A. W., Harigopal, M., Hui, P., Schofield, K., Chhieng, D.C. (2011). Comparison of Affirm VPIII and Papanicolaou Tests in the Detection of Infectious Vaginitis. Am J Clin Pathol. 135(3):442-47.

López-Monteon, A., Gómez-Figueroa, F. S., Ramos-Poceros, G., Guzmán-Gómez, D., Ramos-Ligonio, A. (2013). Codetection of Trichomonas vaginalis and Candida albicans by PCR in urine samples in a lowrisk population attended in a clinic first level in Central Veracruz, Mexico. Biomed Res Int.:1-7.

Mohanty, S., Xess, I., Hassan, F., Kapil, A., Mittal, S., and Tolosa, J. E. (2007). Prevalence and susceptibility to fluconazole of Candida species causing Vulvovaginitis. Indian J Med Res. 21: 216-219.

Novakowska, D., Kurnafiwska, A. B. StrayPederson, B. and Wilczynski, J. (2004). Prevalence of fungi in the vagina, rectum and oral cavity in pregnant diabetic women relation to gestational age and symptoms. Acta Obstetricia Gynecologica.83(3): 251-256.

Saha, P. Mondal, T. and Mandal, A. K. (2018). Kundu P.K."Prevalence of Vulvovaginal Candidiasis and Trichomoniasis among Women of Reproductive Age in a Rural Tertiary Care Hospital in West Bengal, India."IOSR Journal of Dental and Medical Sciences (IOSR-JDMS) 17(9): 45-50.

Taiwo, S. S., Adesiji, Y. O. and Adekanle, D. A. (2007). Screening for syphilis during pregnancy in Nigeria: a practice that must continue. Sex Transm Infect. 83: 357-8.

Uzoh, C. V., Iheukwumere, I. H., Umezurike, K. C., Onyewenjo, S. C. (2016). Prevalence of Candida albicans among Women Attending Federal Medical Centre Asaba, South-South, Nigeria. Advances in Life Science and Technology; 41: 54-57. 